\title{
Sociedade e tecnologia digital: entre incluir ou ser incluída
}

\author{
Adilson Vaz Cabral Filho*
}

Resumo Este artigo procura investigar o conceito e o propósito embutidos nas políticas de inclusão digital desenvolvidas pela sociedade civil brasileira, em especial pelo Comitê pela Democratização da Informática (CDI) e organizações sociais que participam da campanha CRIS - Sociedade da Informação pelo Direito de Comunicar. Será desenvolvido a partir da pesquisa de alguns documentos de referência, dentre eles, o Mapa da Exclusão Digital, realizado por iniciativa do CDI, e de documentos, relatórios e artigos realizados em torno da participação brasileira - como também da América Latina e Caribe - voltados para a participação da sociedade civil na Cúpula Mundial da Sociedade da Informação.

Palavras-chave inclusão digital, políticas de comunicação, democratização da comunicação

\begin{abstract}
This paper investigates the concept and the purpose of the so-called digital inclusion initiatives developed by Brazilian civil society, especially by the Informatics Democratization Comitee (CDI) and social organizations that take part in the CRIS Campaign - Communications Rights in the Information Society. The discussion is based on reference documents, including the Digital Exclusion Map, made by a CDI initiative, and documents and articles about Brazilian participation - as well as that of Latin America and the Caribbean - focusing civil society at the World Summit on the Information Society.
\end{abstract}

Keywords digital inclusion, communication politics, communications democratization.

\section{Introdução}

Para além de serem popularizadas a partir das demandas que a sociedade identifica a partir de suas próprias necessidades de afirmação social e política, as tecnologias digitais vêm sendo bastante disseminadas por projetos desenvolvidos no âmbito da sociedade civil, geralmente pelo formato de cursos voltados para pessoas de baixa renda. Tais iniciativas se fizeram populares pelo nome de inclusão digital, sendo pensadas e implementadas diante da constatação da desigualdade social e econômica, que tende a se agravar caso não incorpore parcelas significativas da sociedade no contexto das novas tecnologias de informação e comunicação. Esses projetos se propõem, portanto, na medida de suas possibilidades, a diminuir as disparidades sociais entre aqueles que têm acesso a essas tecnologias e aqueles que passam a ter acesso não só à informática, como também à Internet.

\footnotetext{
*Professor do Curso de Comunicação Social da UFF. Doutor e Mestre em Comunicação Social pela UMESP e graduado em Comunicação Social, habilitação Publicidade e Propaganda pela UFF.
} 
Segundo Jorge Thadeu Sampaio (2003), Coordenador do Sampa.org - um projeto de inclusão digital do Instituto Florestan Fernandes, em São Paulo -, as iniciativas de inclusão digital são aquelas que visam oferecer à sociedade "os conhecimentos necessários para utilizar com um mínimo de proficiência os recursos de informática e de telecomunicações existentes e dispor de acesso físico regular a esses recursos". Nesse sentido, a inclusão digital se assemelha, portanto, à idéia de alfabetização digital, numa equivalência com a perspectiva da alfabetização no processo de inclusão social, voltando o foco para aqueles que também se encontram no próprio contexto de exclusão social, acrescentando a temática da tecnologia digital no sentido de somar esforços para atenuar essa diferença.

Em 11 de abril de 2003, por ocasião da divulgação do Mapa da Exclusão Digital, iniciativa do Comitê pela Democratização da Informática (CDI) e do Centro de Políticas Sociais da Fundação Getúlio Vargas, com o apoio da Sun Microsystems (empresa norte-americana produtora de equipamentos de informática) e pela USAID (agência do governo norte-americano), o Caderno Especial do jornal O Globo (2003) "Retratos do Brasil: exclusão digital" apresentou uma série de indicadores de eficiência de iniciativas de inclusão digital no país, que se apresentam como política pública em potência para o território nacional e vêm sendo implementadas até mesmo em outros países. Esta publicação confirma com dados atuais o que já sabíamos a respeito do acesso restrito da população brasileira à Internet: somente 8,31\% dos brasileiros possuem acesso à Internet em suas casas e estes se concentram em áreas urbanas, nos bairros de classe média alta. Traduz-se na face digital da conhecida inclusão social.

Áreas rurais, índios, detentos, comunidades ribeirinhas e distantes, portadores de deficiência física e mental, profissionais carentes de repartições públicas, terceira idade, menores infratores... O panorama proporcionado pelas matérias e notas do caderno de $O$ Globo nos faz supor que a excelência de uma política de inclusão digital está na medida da capacidade de levar a tecnologia digital a todas as pessoas em todos os lugares e situações. Partindo da idéia de que é importante para a sociedade apreender ferramentas, recursos e suportes relacionados à tecnologia digital, então, para que a sociedade seja "digitalmente incluída", é preciso que tenha em suas próprias mãos os rumos da tecnologia; em outras palavras, que se permita a apropriação da tecnologia por parte da sociedade. Da forma como se caracteriza a temática da inclusão digital, a sociedade é submetida ao desenvolvimento tecnológico que se manifesta na vida cotidiana através dos seus mais variados setores - o comércio, a escola, etc - e não é possível se pensar essa temática como em equivalência com a inclusão social.

As ações necessárias para a inclusão social envolvem diversas áreas como saúde, educação, habitação, saneamento básico, etc. Oferecer saúde à população não é simplesmente oferecer determinados tipos de remédios ou médicos, pautados numa determinada concepção de saúde ou corpo são, mas sim proporcionar o acesso ao sistema de saúde oferecido pelo Estado ao conjunto da população. Poderíamos dizer o mesmo da escola em relação ao processo educacional, das moradias em relação ao sistema educacional, etc.

Incluir a perspectiva tecnológica envolve apreender o discurso da tecnologia, não apenas os comandos de determinados programas para a execução de determinados fins, não apenas qualificar melhor as pessoas para o mundo do trabalho, mas sim a capacidade de influir na decisão sobre a importância e as finalidades da tecnologia digital, o que em si é uma postura que está diretamente relacionada a uma perspectiva de inclusão/alfabetização digital, de política pública e de construção de cidadania, não apenas de quem consome e assimila um conhecimento já estruturado e direcionado para determinados fins. 


\section{Da inclusão digital ao direito de comunicar}

Carecemos, portanto, de um conceito de inclusão digital mais amplo, que proporcione uma dimensão social e política para o papel que a tecnologia representa para a sociedade, visando "fomentar o exercício da cidadania, para dar voz às comunidades e setores que normalmente não têm acesso à grande mídia e para apoiar a organização e o adensamento da malha de relações comunicativas entre os atores da sociedade civil que constituem a esfera pública" (SAMPAIO, 2003).

Este processo implicaria uma reorientação estratégica em relação ao que costumeiramente constitui o propósito dos projetos de inclusão digital, pois, ao invés de serem apresentados como um conhecimento já acabado sobre o que a tecnologia digital possibilita, a sociedade, ela mesma, deveria manifestar suas demandas em relação aos benefícios que as tecnologias podem proporcionar, tornando-se assim, sujeito do processo de inclusão digital, afirmando sua cultura e, por conseguinte, sua cidadania.

Nesse sentido toda uma linha de pesquisadores no campo da comunicação comunitária vem desenvolvendo suas pesquisas e chegando a suas conclusões, apontando metodologias de trabalho. Santoro (1989) já apontava a necessidade de trabalhar com o vídeo popular no sentido de colaborar "para que as classes populares possam expressar a sua própria visão de mundo, informar-se, registrar sua história". Peruzzo (1998) salienta que o poder é a questão central da temática da participação, devendo ser ele solidário e partilhado, formado por características participativas da sociedade propostas por Pedro Demo, dentre as quais destacamos as idéias de que "o poder vem de baixo para cima, sendo detentor dele o próprio movimento [...] quem está no poder não é dono dele, tendo-o recebido da comunidade, por delegação" (PERUZZO, 1998, p. 88).

O processo de apreensão do discurso tecnológico não é diferente do modo de produção da comunicação ou mesmo da organização popular, visto que diretamente relacionado à capacidade de acesso, produção, controle e gestão dos meios, programas recursos e serviços que se podem conceber a partir da tecnologia digital. Dessa forma, a pergunta "para que incluir a tecnologia digital na sociedade?" pode ser respondida de modo mais claro: mais do que correr atrás do tempo perdido, imagem relacionada aos novos incluídos que têm mais chances de ser assimilados pelo mercado de trabalho, há uma vinculação direta com a idéia de afirmação da cidadania, que precisa ser buscada na relação com o meio.

Isso é o que uma série de organizações sociais vem tentando desenvolver em torno da campanha intitulada CRIS - Communications Right on the Information Society (em português, Sociedade da Informação pelo Direito de Comunicar). A campanha CRIS foi implementada em novembro de 2001 por organizações não-governamentais (ONGs) e indivíduos em todo o mundo, propondo estabelecer, como marco geral de discussão, a aplicação do desenvolvimento tecnológico para melhorar a situação dos direitos humanos. O foco central da campanha é a comunicação como um direito, disseminando a conscientização sobre o papel da comunicação na vida das pessoas, como um direito que, uma vez garantido, viabiliza e fortalece a luta por todos os direitos fundamentais. No Brasil, a campanha conta com a participação de várias organizações sociais e ganha maior dimensão em função da Cúpula Mundial da Sociedade da Informação, concebida em duas fases, uma em dezembro de 2003, em Genebra, outra em 2005, na Tunísia. 


\section{Trocando em miúdos ...}

Nas imediações, entretanto, o debate envolvendo a preparação para a Cúpula vem acontecendo de forma bem mais intensa e um documento síntese de referência foi elaborado pelo Grupo de Trabalho da Sociedade Civil em Conteúdos e Temas, por ocasião da $2^{\mathrm{a}}$ reunião preparatória da Cúpula Mundial e se intitula "Sete deveres: princípios prioritários propostos pela sociedade civil" (2003). Resume, de forma bastante precisa, os princípios para o entendimento do que a sociedade civil, articulada em torno da campanha CRIS, visualiza como prioritário para a implementação de uma Sociedade da Informação nos diversos países, a saber: desenvolvimento sustentável; governabilidade democrática; alfabetização, educação e pesquisa; direitos humanos; conhecimento global de domínio público; diversidade cultural e lingüística; segurança da informação.

Sintetiza a idéia de que não há possibilidade de implementar a tecnologia digital na sociedade sem que haja uma planificação mais ampla, envolvendo outros setores também determinantes, visando oferecer um conjunto de condições propícias à assimilação dos benefícios que podem ser proporcionados. Além disso, sugere que a disposição para implementar esse novo cenário seja conjunta por parte de governos, empresas e sociedade civil, mas que não seja imposta a partir de um setor em relação aos outros.

Reivindica uma atenção aos aspectos relacionados à expansão tecnológica, colocando-os no mesmo patamar de ações historicamente prioritárias no contexto social, não como uma temática relacionada à penetração da tecnologia no cotidiano da sociedade, que nos aproximaria do conceito de sociedade da informação, apresentado por Takahashi (2000, p.3) como "uma nova era em que a informação flui a velocidades e em quantidades há apenas poucos anos inimagináveis, assumindo valores sociais e econômicos fundamentais". Um importante indicador dessa movimentação foi observado por Mattelart (2002, p.124), quando afirma que desde a Conferência Administrativa Mundial do Rádio (WARC), organizada pela UIT - União Internacional das Telecomunicações em 1979, "o deslocamento dos debates sobre a sociedade do futuro para organismos de competência técnica em detrimento de instituições com vocação cultural como a UNESCO". Coincidentemente, a UIT é co-organizadora da Cúpula Mundial para a Sociedade da Informação (http://www.itu.int/wsis).

A especificidade da temática da informação (e por que não dizer também, da comunicação) está relacionada diretamente à capacidade de se apropriar dos processos e dos conteúdos disponibilizados, ou seja, de conhecer os propósitos e as possibilidades das tecnologias que se implementam e se pode implementar, o que nos leva à idéia mais ampla e qualificada de uma sociedade do conhecimento. José Marques de Melo (2002, p. 42) elencou uma série de impasses a serem superados para o enfrentamento do assim chamado 'apartheid digital', dentre os quais vale ressaltar a reciclagem e a renovação de recursos humanos e a produção de conhecimento socialmente relevante. Mais interessante ainda seria pensar numa fusão desses dois tópicos: a produção de conhecimento socialmente interessante por recursos humanos reciclados e renovados e a medida da plena inclusão estariam exatamente na combinação desses aspectos.

É preciso, portanto, conhecer para ser informado e incluído. Tomar por base um conceito de inclusão digital que parte da conscientização do incluído implica necessariamente implementar políticas de integração que sejam facilmente assimiladas e socialmente construídas. Victor van Oeyen (2003), fundador da campanha CRIS na Bolívia, afirmou numa recente apresentação que o conceito vago e problemático de "Sociedade de Informação" poderia ser substituído pelo preciso "Direito Humano à Comunicação", garantido "a todos os segmentos da população, 
incluindo neste (direito) sua participação ativa, inclusive na produção de conteúdo e o direito à propriedade dos meios para produzir tais conteúdos", que contemplaria fatores tais como a "propriedade comunitária, conteúdo local, tecnologia apropriada, linguagem e pertinência cultural e convergência técnica".

As duas diferentes trajetórias para um entendimento mais qualificado no sentido de um maior engajamento da sociedade civil podem agora se encontrar numa perspectiva comum: a inclusão digital entendida como um aspecto da inclusão social e as demandas específicas no campo comunicacional para a promoção da inclusão digital convergem para uma pauta de reivindicações comuns no cenário da democratização da comunicação, no sentido do que já tive a oportunidade de abordar em oportunidades anteriores: "mostrar as possibilidades de utilização dos veículos de comunicação diante da configuração do mercado (atividade-fim) e principalmente estimular a produção por parte das comunidades" (CABRAL, 2003, p.6).

\section{... Cada vez mais miúdos}

Isso resulta numa revitalização dos sete deveres propostos pela sociedade civil, no sentido de uma possível apropriação por parte das populações, para além dos princípios governamentais que resultem em cartas de compromisso multilateral com limitada ressonância na vida cotidiana da sociedade. A releitura que se segue dos princípios propostos é um esboço de projetos que podem derivar das mais diversas idéias de materialização desses princípios nos mais diversos setores sociais.

O desenvolvimento sustentável está relacionado à expansão da informática e da Internet em todos os lugares e em todas as classes sociais, bem como etnias, gêneros, idades e todos aqueles segmentos sociais desejosos de se apropriar da forma que melhor entenderem. O ambiente da informática e da Internet também precisa ser acolhedor (acessível/amigável - veremos mais à frente) para esses segmentos e aberto o suficiente para ser construído de acordo com os interesses da coletividade.

A governabilidade democrática deve ser estabelecida de modo a integrar as pessoas, tornando as estruturas de governo transparentes e acessíveis no âmbito dos municípios, estados, países e regiões, bem como do planeta. Um bom exemplo é a apropriação de mecanismos de orçamento participativo para o ambiente digital: que não se traduza em privilegiar informações através dos computadores, mas que torne a informação cada vez mais próxima a um número cada vez maior de pessoas.

A educação para a informática e para o uso da Internet precisa ser planejada desde os primeiros níveis de ensino. Sem preconceitos ou imposições, sem substituir o analógico pelo digital, mas reforçando a capacidade cognitiva dos alunos e guiando a descoberta de novos horizontes. $\mathrm{O}$ acesso aos meios deve estimular a capacidade produtiva, apresentando os mais diferentes recursos e serviços disponíveis, sendo que, para isso, é necessária uma atualização constante dos professores, pedagogos e técnicos que trabalham com o conteúdo.

Do ponto de vista do conteúdo disponibilizado e que se fomenta nos espaços de capacitação, o conhecimento e a defesa dos direitos humanos precisam ser preservados, visando criar ambientes de compartilhamento, de debates, de informação sobre garantias individuais, de valorização da auto-estima, de valorização das características sociais e da construção de identidades que fortaleçam a solidariedade e a integração dos povos. Como direito humano também podemos 
considerar aqui o direito ao próprio ato de comunicar e definir a convivência com a tecnologia que se apresenta de modo impositivo na vida social.

Que as informações de interesse público estejam acessíveis, cabendo ao conjunto da sociedade definir a sua dimensão. Para acessar, no entanto, é necessário conhecer suas finalidades, seu funcionamento e a relação direta com o cotidiano das pessoas. Sendo assim, não se trata apenas de disponibilizar uma significativa quantidade de informação numa considerável base de dados, mas sim capacitar a população a compreender, assimilar, utilizar e ser capaz de se posicionar criticamente em relação a esses dados.

Que os realizadores da indústria da informática - no tocante à infra-estrutura e aplicativos e criadores de recursos e serviços na Internet sejam estimulados, mediante programas de incentivo governamentais e/ou empresariais, a contemplar cada vez mais as possibilidades de expressão das populações emergentes e ainda não consideravelmente 'incluídas', proporcionando as mais variadas interfaces nos mais diversos idiomas e acessos nos mais variados contextos socioculturais.

E que o sistema que permite todo esse fluxo a partir da grande rede de computadores não seja impeditivo das possibilidades de ação dos usuários, no sentido de um injustificado combate ao "ciberterrorismo" que leve à realização de ações de violação de propriedade através da instalação não autorizada de programas ou componentes internos dentro da configuração dos micros, como também da apropriação de dados visando formar cadastros públicos para a utilização dos mais diversos empreendimentos em técnicas de venda conhecidas como spam. Isso implica um maior controle por parte da sociedade daquilo que se está consumindo, onde será fundamental a participação de especialistas dispostos a traduzir esse discurso digital para o conjunto da população.

Esses sete deveres são bons princípios que podem dar origem a uma série de propostas concretas de ação nos mais variados setores. Inspiram várias abordagens que podem se traduzir na disseminação de exemplos ou na manifestação de denúncias, revelando de modo mais concreto a real disposição dos governos, das empresas e, porque não dizer, da própria sociedade civil em relação a uma política pública mais efetiva no tocante à inclusão digital.

Afinal de contas, às vésperas de uma reunião de governos de todo o mundo que também contará com a presença intensiva da iniciativa privada, a sociedade civil se depara com uma série de contradições que encontram ressonância nessa era digital: uma tecnologia que liberta e potencializa, mas que não é acessível a todos, nem mesmo vem contribuindo para a melhoria dos problemas sociais; que potencializa o compartilhamento, mas nossa sociedade vive em estado de guerrilha. E, nesse cenário, o que se pode concluir diante da capacidade de ação e proposição por parte das organizações sociais é que estamos diante de um impasse onde a ação direta sem visão mais ampla e com algum embasamento político é substituída pela construção globalizada de uma intervenção extremamente qualificada, mas carente de organicidade na maioria dos casos.

\section{Analfabetismo digital zero}

Para além desta situação que carece de formulações mais precisas e aplicáveis à nossa realidade, os atores sociais que se mobilizam em torno desta temática social têm uma responsabilidade determinante no sentido de saber agenciar a sociedade digitalmente excluída para uma formação de uma consciência crítica do papel que a tecnologia representa em suas vidas. E 
fundamentalmente também proporcionar uma reflexão e ações sobre a idéia de inclusão digital que envolva o conjunto de suas variáveis determinantes no âmbito das políticas públicas de Estado, bem como no papel da iniciativa privada e da interação entre esses dois setores.

Nesse sentido, propomos alguns eixos de atuação necessários ao debate e diretamente relacionados com os pontos fundamentais para a implementação de uma Sociedade da Informação que seja também do Conhecimento, afirmativa da cidadania e que exerça em sua plenitude o direito a comunicar:

Acesso aos domicílios - a metodologia dos principais institutos de pesquisa trabalha com uma investigação que parte de um conceito mais constante da idéia de usuário da informática e da Internet; usuário é aquele que tem. Entretanto, a maior parte do acesso à Internet e ao próprio meio digital é inconstante e, de certa forma, não é quantificável, devido a sua informalidade. Esse acesso se dá no trabalho, na escola, num ponto de acesso público (de modo mais limitado, porém significativo, devido inclusive a sua capacidade de expansão). Uma questão a ser colocada nesses mecanismos de mensuração é a necessidade de se incorporarem essas redes não convencionais de acesso no contexto das políticas públicas de incentivo, estimulando a criação de iniciativas descentralizadas de apoio à inclusão digital, que partam do próprio cotidiano do público beneficiado.

Outra questão está diretamente relacionada ao próprio usuário doméstico. Esse número não é significativo devido a uma série de variáveis que precisam ser urgentemente colocadas em debate: o preço dos micros - que vem caindo, mas ainda se encontra num patamar inacessível a boa parte da população - não se resolve com o subsídio a programas de criação de micros populares de configuração limitada. Na verdade estão é limitando o ambiente da informática e da Internet a ser apresentado às pessoas. Da mesma forma, os programas a serem usados precisam e já podem ser gratuitos e de código aberto, para que estejam efetivamente à disposição das pessoas, tanto no sentido econômico, quanto de apreensão das mais variadas dimensões de aproveitamento da tecnologia. Além disso, o preço e a qualidade dos serviços de provimento de energia elétrica, de telefonia e de acesso à Internet precisam ser repensados dentro de uma ótica que possa trabalhar para o incentivo à inclusão, não contra a população que deseja ser incluída.

Um ponto fundamental nesses mecanismos de inclusão, que não envolve o debate sobre o quanto as pessoas e as famílias estariam dispostas a gastar para ter computadores e acesso à Internet em casa está relacionado ao desenvolvimento de pontos de acesso públicos e gratuitos - os assim chamados telecentros. ${ }^{1}$ Sérgio Amadeu da Silveira, no seu preciso livro "Exclusão digital: a miséria na era da informação", lista alguns modelos de telecentros já implementados à época no Brasil: os já citados Sampa.org e CDI; o Farol do Saber, da Prefeitura de Curitiba; o e-cidadania, da Prefeitura de São Paulo. Para Amadeu, a infoinclusão é estratégica porque "é preciso inserir as pessoas no dilúvio informacional das redes e orientá-las sobre como obter conhecimento". Segundo ele, a pobreza será reduzida pela

construção de coletivos sociais inteligentes, capazes de qualificar as pessoas para a nova economia e para as novas formas de sociabilidade, permitindo que se utilizem as ferramentas de compartilhamento de

\footnotetext{
${ }^{1}$ Um dado interessante sobre o Mapa da Exclusão Digital revelado pela IDG Now (2003) no artigo "Estudo aponta apartheid digital no País" (003/04/0012): "Os três melhores Estados em inclusão digital doméstica são: Distrito Federal, São Paulo e Rio de Janeiro. Já no quesito inclusão digital na escola, o Distrito Federal perde a liderança para o Paraná."
} 
conhecimento para exigir direitos, alargar a cidadania e melhorar as

condições de vida" (SILVEIRA, 2001, p. 21).

Outra questão bem sutil, mas não menos determinante, está diretamente relacionada à eficiência das iniciativas de inclusão digital: as estratégias de capacitação. Nesse ponto, não podemos tratar apenas de pessoas não incluídas, mas também daqueles que irão proporcionar um envolvimento mais pleno com o ambiente informacional. Não somente professores, mas facilitadores também, pessoas que contarão com disposição para compartilhar o desenvolvimento de estratégias de incremento do acesso por parte da população, aplicadas em novos programas, novos recursos de compartilhamento. Como os blogs, por exemplo, que não introduzem nenhum componente novo de linguagem, mas tornam as possibilidades de criação de homepages mais acessíveis às pessoas de um modo geral e fazem com que se sintam mais à vontade para se iniciar na rede. Nesse sentido, estamos assumindo um conceito mais qualificado de inclusão, que envolve o aproveitamento de recursos e serviços disponíveis na rede por parte do público. Uma definição que, com certeza, faria cair as estatísticas que incorporam somente o acesso como delimitador de quem é ou não incluído. Usuários que geralmente sub-utilizam a Internet, aproveitando em sua maioria o e-mail para ler e escrever e homepages para acessar, mas timidamente produzir.

Capacitadores serão aqueles que, numa dimensão mais ampla, apresentam o ambiente digital e virtual em suas potencialidades de aproveitamento, de modo diretamente relacionado às realidades de cada cultura e de cada grupo, estabelecido de maneira territorial ou minimamente com um componente de identidade que os identifique.

Um ponto também bastante abrangente, que diz respeito à interface entre homem e máquina. Não adianta apresentar um ambiente como determinante de um reordenamento espaço-temporal, como otimizador de muitas tarefas e necessidades que serão cada vez mais colocadas no cotidiano das pessoas, se as pessoas que efetivamente compõem uma das partes desse jogo interativo não se sentem animadas a participar. Uma série de fatores se impõe como desafio por parte dos desenvolvedores de equipamentos, programas e serviços, e se restringem a três aspectos básicos (CABRAL, 1999, p. 4) que são: a acessibilidade - um suporte, dentre outras tarefas, que suprima toda a distância que separa a iniciação do sistema à apresentação de sua interface; a portabilidade - que facilite o transporte e respeite a relação do usuário com seu ambiente, seja em casa, no trabalho ou no lazer - e a "amigabilidade" - capacidade de realizar tarefas longas e repetitivas de maneira automática, ou ainda facilitando a instalação e a utilização dos comandos. E, além disso, é imprescindível introduzir a Internet na cultura das organizações, na produção de seus conteúdos, na divulgação de seus informativos e da sua publicidade, na otimização de suas transações financeiras e do armazenamento de suas informações, bem como de sua socialização junto aos diferentes públicos.

Apresentado de forma esquemática, esse quadro de possíveis ações ficaria assim:

\section{Em domicilios}

Ações: redução dos preços dos micros e programas; incentivo ao desenvolvimento de micros e programas acessíveis sem perda de qualidade; Incentivo ao software livre e de código aberto

Setores: iniciativa pública e privada com participação da sociedade civil na gestão 


\section{Em telecentros}

Ações: escolas, bibliotecas, postos de saúde, correios, órgãos públicos, shoppings, etc.

Setores: sociedade civil em parceria com iniciativa pública e privada

Via capacitação

Ações: facilitadores / professores, pessoas em geral: de grupos e comunidades territoriais locais ou distantes.

Setores: sociedade civil com apoio da iniciativa pública e privada

Via melhoria da interface

Ações: desenvolvimento de pesquisa e produção, visando ambientes mais amigáveis, acessíveis e portáteis.

Setores: iniciativa privada, com incentivo governamental e co-gestão pública

\section{Concluindo: proporcionaremos a inclusão digital ou nos deixaremos ser incluídos?}

Um gerenciamento do desenvolvimento dessas ações em parceria poderia ser implementado de modo compartilhado com setores oriundos de organizações e movimentos sociais, bem como organizações e cursos na academia. A integração multidisciplinar necessária no desenvolvimento integrado de iniciativas capazes de contribuir para a superação de condições adversas em áreas como educação, saúde e capacitação para acesso ao emprego é um componente fundamental no sucesso das várias empreitadas desenvolvidas ao longo desses anos. No entanto, se tais políticas não forem adotadas integralmente, apropriando-se dos recursos instrumentais, mas também do fortalecimento de laços comunitários comprometidos com o desenvolvimento de soluções que efetivamente transformem as condições de vida das pessoas nos diversos locais.

Um bom exemplo a servir como paradigma para articular atores que se fazem cada vez mais necessários, visando o compartilhamento de ações para o desenvolvimento de esforços urgentes que sejam o resultado do papel que a tecnologia pode vir a ocupar em nossa sociedade, contemplando a geração de riquezas por parte de nosso povo, como também o incentivo à pesquisa, ao conhecimento e à educação. Essa sim, a contribuição que a tecnologia pode oferecer para a consolidação de um mundo mais solidário, desde que a sociedade a assuma conscientemente. 


\section{Referências}

CABRAL, Adilson. E a massa virou rede In: CONGRESSO DA SOCIEDADE INTERDISCIPLINAR DA COMUNICAÇÃO. 1999, Rio de Janeiro. Anais eletrônicos..., São Paulo: Intercom, 1999.

Um mito de concreto: pistas para um movimento pela democratização da comunicação. Disponível em: <http://www.intercom.org.br/papers/xxi-ci/gt27/GT2702.PDF>. Acesso em: 21 abr. 2003. Texto enviado para o Congresso da Intercom de 1998.

Sociedade e tecnologia digital, entre incluir ou ser incluída In: CONGRESSO BRASILEIRO DE CIÊNCIAS DA COMUNICAÇÃO. 26., 2003, Belo Horizonte-MG. Anais eletrônicos... São Paulo: Intercom, 2003.

GRUPO DE TRABAJO DE SOCIEDAD CIVIL EN CONTENIDOS Y TEMAS. Comité de Redacción. "Siete principios": prioridades propuestas por sociedad civil. Disponível em: $<$ http://lac.derechos.apc.org/wsis/cdocs.shtml?x=10445>. Acesso em: 22 abr. 2003. Cumbre Mundial sobre la Sociedad de la Información, Genebra, fev. 2003.

IDG NOW. Estudo aponta apartheid digital no País. Disponível em: <http://www.businessstandard.com.br/bs/noticias/2003/04/0012>. Acesso em: 22 abr. 2003.

MATELLART, Armand. História da sociedade da informação. São Paulo: Loyola, 2002.

MELO, José Marques de. A muralha digital: desafios brasileiros para construir uma sociedade do conhecimento. In: PERUZZO, Cicília; BRITTES, Juçara. Sociedade da informação e novas mídias: participação ou exclusão? São Paulo: Intercom, 2002.

O GLOBO. Caderno Especial Retratos do Brasil: exclusão digital. Rio de Janeiro, 11 abr. 2003.

OEYEN, Victor van. Otra comunicación es posible. Disponível em: <http://www.apc.org/apps/img_upload/5ba65079e0c45cd29dfdb3e618dda731/otra_comunicacio n_posible.doc>. Acesso em: 22 abr. 2003.

PERUZZO, Cicília. Comunicação nos movimentos populares: a participação na construção da cidadania. Petrópolis: Vozes, 1998.

SAMPAIO, Jorge Thadeu. $O$ que é inclusão digital? Disponível em: <http://www.sampa.org/sgc/base/arq.asp?idarq=92>. Acesso em: 20 abr. 2003.

SANTORO, L.F. A imagem nas mãos: o vídeo popular no Brasil. São Paulo: Summus Editorial, 1989. $135 \mathrm{p}$.

SILVEIRA, Sérgio Amadeu da. Exclusão digital: a miséria na era da informação. São Paulo: Perseu Abramo, 2001.

TAKAHASHI, Tadao (Org.). Sociedade da Informação no Brasil: livro verde. Brasília, Ministério da Ciência e Tecnologia, 2000. 